\title{
Adaptation of Artificial Intelligence to Predict Concrete Strength
}

\author{
Ali Laftaa Abbas, Suhad Mohammad Abid and Jinan Laftaa Abbas \\ Civil Engineering Department, College of Engineering, Diyala University,Baqoubah, Diyala, Iraq
}

Received: August 27, 2013 / Accepted: September 28, 2013 / Published: October 25, 2013.

\begin{abstract}
In past, different methods were used to predict the strength of concrete. Artificial intelligence in term of the fuzzy-logic system was used in this study. A new model was proposed and developed for the prediction of concrete compressive strength at different ages. The variables used in the prediction models were from the knowledge of the mix itself, i.e., mix proportion elements. The models providea good estimation of compressive strength and yielded good correlations with the data used in this study. Moreover, the proposed models proved to bea significant tool in predicting compressive strength of different concretes in spite of variations in the results.
\end{abstract}

Key words: Construction materials, concrete strength, fuzzy logic.

\section{Introduction}

Concrete is a versatile construction material owing to the benefits it provides in term of strength, durability, availability, adaptability and economy. Great efforts have been made to improve the quality of concrete by various means in order to raise and maximize its level of performance. It is such a construction material that is widely used in the world. The advantages of concrete are low cost, availability of construction, workability, durability and convenient compressive strength that make it popular near engineers and builders. However, these advantages seriously depend on the correct mix, placing and curing [1]. Inthe construction industry, strength is a primary criterion in selecting a concrete for a particularapplication. Concrete used for construction gains strength over a long period of time after pouring. The characteristic strength of concrete is defined as the compressive strength of a sample that has been aged for 28 days [2].

Inthe construction industry, strength is a primary.

Correspondingauthor: Ali Laftaa Abbas, Ph.D., lecturer, research fields: civil engineering and structureengineering andmaterials engineering. E-mail: adel_alkayali@yahoo.com.
Neither waiting 28 days from such a test would serve the rapidity of construction, nor neglecting it, would serve the quality control process on concrete in large construction sites. Therefore, rapid and reliable prediction for the strength of concrete would be of great significance [3]. For example, it provides a chance to make the necessary adjustment to the mix proportion used to avoid the situation where concrete does not reach the required design strength or concrete that is unnecessarily strong, and also, for more economic use of raw materials and fewer construction failures, hence reducing construction cost.

Prediction of concrete strength, therefore, has been an active area of research and a Considerable number of studies have been carried out.

Many attempts have been made to obtain a suitable mathematical model which is capable of predictingthe strength of concrete at various ages with acceptable (high) accuracy [4].

For the last two decades, the different modeling methods based on artificial neural networks (ANN) and fuzzy logic (FL) systems have become popular and has been used by many researchers for a variety of 
engineering applications. The basic strategy for developing ANN and FL systems based models for material behavior is to train ANN and FL systems on the results of a series of experiments using that material. If the experimental results contain the relevant information about the material behavior, then the trained ANN and FL systems will contain sufficient information about material's behavior to qualify as a material model. Such a trained ANN and FL systems not only would be able to reproduce the experimental results, but also they would be able to approximate the results in other experiments trough their generalization capability [5-9].

\section{Prediction Methods for Strength of Concrete}

Under the currently quicker pace of construction, there was a great need for more production of concrete with persisting on the conformability of the quality of the produced concrete with the standards and specifications. The compliance of any produced concrete with these specifications Consider to be significant evidence for good concrete. The specifications, generally, include a statement of physical and chemical requirements. Among all, strength tests are prescribed by all specifications, because the compressive strength of concrete in the hardened condition is very important, and perhaps it is the most obviously required for structural use.

Specifications usually specifythe test method as well as the age ofthe test. Strength of concrete, as specified by all the standards, is very important (from 1 to 28 days), because the early development of strength (early gain in strength) is very important. But, as early strength of concrete is important, strength at later ages is more important, because after all, it is this property which is relied upon in structural design of concrete as a construction material. The traditional 28 days standard test has been found to givea general index of the overall quality (used in quality control process) and acceptance of concrete, and has served well for so many years. Neither waiting for the result of such a test would serve the rapidity of construction, nor, neglecting it would serve the quality control process of the concrete. Moreover, rapid and reliable prediction of the results of 28 days strength test as early as possible would be of satisfaction for all parties instead of waiting for the traditional 28 days results [4].

A number of improved prediction techniques have been proposed by including empirical or computational modeling, statistical techniques and artificial intelligence approaches.

(1) Computational modeling:

Many attempts have been made for modeling this process through the use of computational techniques such as finite element analysis. These techniques often based on the complex thermodynamic equations that underpin the aging of concrete.In addition, the computational complexity of the models is prohibited in many cases, requiring non-proprietary mathematical tools.

(2) Statistical techniques:

A number of research efforts have concentrated on using multivariable regression models to improve the accuracy of predictions.

Statistical models have the attraction that once fitted they can be used to perform predictions much more quickly than other modeling techniques, and are correspondingly simpler to implement in software.

Popovics [10], augments Abrams model, a widely accepted equation relating the water cement ratio $\mathrm{w} / \mathrm{c}$ of concrete to its strength with additional variables such as slump, and uses least square regression to determine equation coefficients. Using this approach improved strength prediction and insights into concrete compositions were achieved. Nagesha et al. [2] used multivariable regression techniques on concrete composition data to predict 28 days compressive strength with reasonable accuracy, proposing a formula readily applicable for on-site use.

A part of its speed, statistical modeling has the advantage over other techniques that it is 
mathematically rigorous and can be used to define confidence interval for the predictions. This is especially true when comparing statistical modeling with artificial intelligence techniques. Statistical analysis can also provide insight into the key factors influencing 28 days compressive strength through correlation analysis. For these reasons, statistical analysis was chosen to bea technique for strength prediction of this paper.

(3) Neural Networks Fuzzy Logic

Because strengthening of concrete is a complex non-linear process dependent on many variables, it is a problem well suited to the artificial intelligence concept known as artificial neural networks (ANNs) and Fuzzy Logic. Artificial neural networks and fuzzy logic have been widely used in many areas in civil engineering applications.

The concept of "fuzzy set" was introduced by Zadeh [11], who pioneered the development of fuzzy logic instead of Aristotelian logic which has two possibilities only. The fuzzy logic concept provides a natural way of dealing with problems in which the source of imprecision is the absence of sharply defined criteria rather than the presence of random variables. Fuzzy approach considers cases where linguistic uncertainties play some role in the control mechanism of the phenomena concerned. Herein, uncertainties do not mean random, probabilistic and stochastic variations, all of which are based on the numerical data. Zadeh has motivated his work on fuzzy logic with the observation that the key elements in human thinking are not numbers but levels of fuzzy sets. Further, he saw each linguistic word in a natural language as a summarized description of a fuzzy subset of a universe of discourse representing the meaning of this word. In consequence, he introduced linguistic variables as variables whose values are sentences in a natural or artificial language [12].

\section{Basic Fuzzy Definitions and Terminology}

Many of the fundamental techniques of fuzzy systems are widely available so only a fairly brief in the following $[13,14]$ :

\subsection{Classical (Crisp)\& Fuzzy Sets}

Fuzzy sets can be considered as a generalization of the classical "crisp sets". Instead of strictly distinguishing objects that belong to a given set and those that do not, fuzzy sets allow "grades of membership function" expressed by real numbers between 0 and 1 .

For example, a classical set $\mathrm{A}$ of real numbers $\mathrm{X}$ (the universe of discourse) for $\mathrm{x}$ greater than 6 can be expressed as a set of ordered pairs:

$$
\mathrm{A}=\{\mathrm{x}, \mathrm{FA}(\mathrm{x}) \mid \mathrm{x}>6\}, \mathrm{x} \in \mathrm{X},
$$

where, FA ( $\mathrm{x})$ are the characteristic function of the crisp set at:

$$
\mathrm{F}_{\mathrm{A}}(x)=\left\{\begin{array}{l}
1 \text { if } x \in \mathrm{A} \\
0 \text { if } x \notin \mathrm{A}
\end{array}\right.
$$

while, a fuzzy set $\mathrm{A}$ in $\mathrm{X}$ is defined as: $\mathrm{A}=\{x, \mu \mathrm{A}(x) \mid x$ $\notin \mathrm{X}$, where $\mu \mathrm{A}(x)$ is called the membership function (MF) of $\mathrm{x}$ in $\mathrm{A}: \mu \mathrm{A}: \mathrm{X} \rightarrow[0.1]$.

\subsection{Membership Function}

A membership function associated with a given fuzzy set map an input value with its appropriate membership value between 0 and 1 as shown in Fig. 1 . There are different shapes of MFs. The function itself can be an arbitrary curve whose shape we can define as a function that suits us from the point of view of simplicity, convenience, and efficiency.

\subsection{Fuzzy Logic}

Fuzzy logic is a way of mapping human knowledge into a form useable by a computer; it is the foundation for computing with words. Fuzzy logic as a multi-valued logic defines the logic union(OR) intersection (AND), complement (NOT), etc. operations of fuzzy sets in a similar way to Boolean logic (two-valued) and classic set theory. Fig. 2 shows the structure of the prediction model.

\subsection{Basic Operation on Fuzzy Sets}

OR (union): A common fuzzy disjunction operator is the maximum operator: 


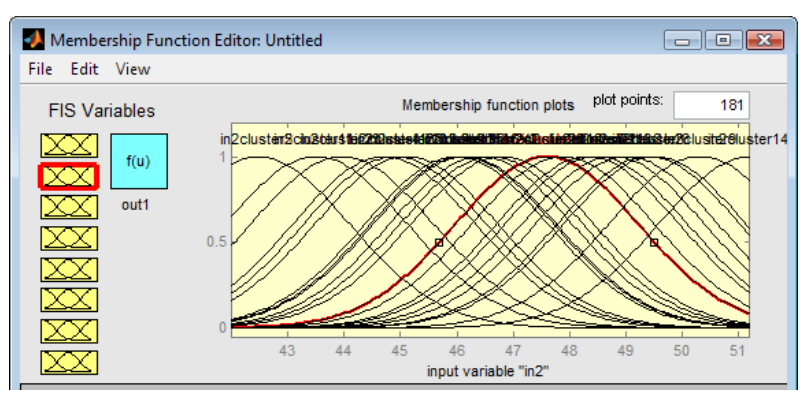

Fig. 1 Fuzzy membership functions for s/a.

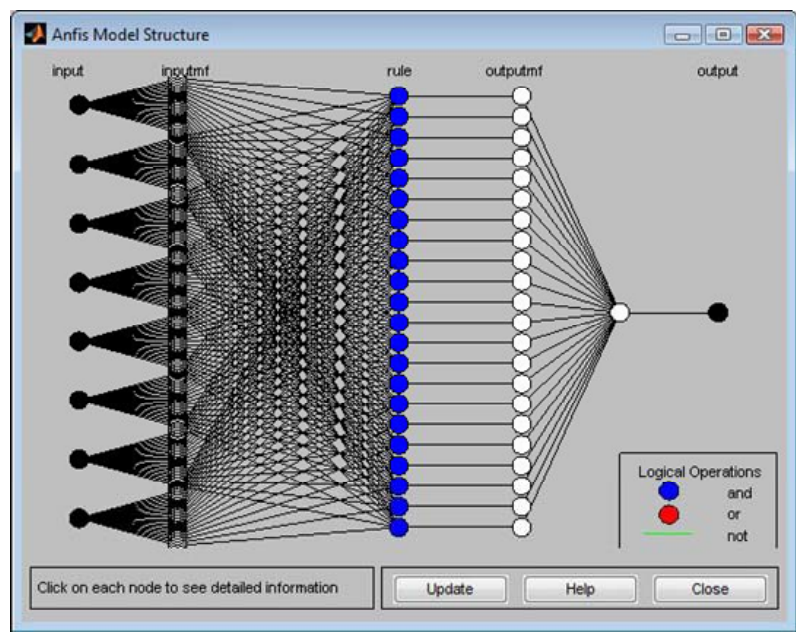

Fig. 2 Prediction model structure.

$\mu \mathrm{AUB}(x)=\max \{\mu \mathrm{A}(x), \mu \mathrm{B}(x)\}$,

AND (intersection): A common fuzzy conjunction operator is the min operator:

$\mu \mathrm{A} \cap \mathrm{B}(x)=\min \{\mu \mathrm{A}(x), \mu \mathrm{B}(x)\}$,

NOT operation: The complement of a fuzzy set $\mathrm{A}$ is defined as: $\mu \overline{\mathrm{A}}(x)=1-\mu \mathrm{A}(x)$.

The applications of fuzzy relations include areas such as fuzzy control and decision making.The classical relations in general are structures that represent the presence or absence of correlation or interaction among elements of various sets.

\subsection{Fuzzy IF-THEN Rules and Fuzzy Inference}

In most engineering control applications nowadays, the fuzzy rules are expressed as If-Then configuration,e.g., IF $\mathrm{x}$ is $\mathrm{A}$ then $\mathrm{y}$ is $\mathrm{B}$, or in short: IF $\mathrm{A}$ THEN B: $\mathrm{A} \rightarrow \mathrm{B}$, where $\mathrm{A}$ and $\mathrm{B}$ are linguistic values defined by fuzzy sets on the ranges (universe of discourses) $\mathrm{X}$ and $\mathrm{Y}$, respectively as shown in Fig. 3. The if-part of the rule " $\mathrm{x}$ is $\mathrm{A}$ " is called the antecedent or premise, while the then-part of the rule " $y$ is B" is called the consequent or conclusion figure [15].

The process of inference is cast in terms of composition of a given fact with a given rule, which leads to the term compositional rule of inference.The net effect is a possibility distribution over the domain of definition of the consequent variable. Fig. 4 demonsterates Fuzzy Rules Inference Engine.

We now use computer simulation to demonstrate the fuzzy controller behavior. The simulation is conducted using the MATLAB 7.6 R2008a Simulink and MATLAB Fuzzy Logic Toolbox.The designed and investigated Subway Train Speed Control System using Fuzzy Controller is depicted in Fig. 5.

\section{Experimental Program}

The data were imported from literature belong to Jee Namyong et al. [16]. Tablel shows the physical propertiesofthe materials used. Table 2 shows full details of the data imported and used to check the proposed model. The data comprises on 59 different kinds of mixture witha specified compressive strength of 18-27 MPa, a w/c ratio of $0.39-0.62$, maximum

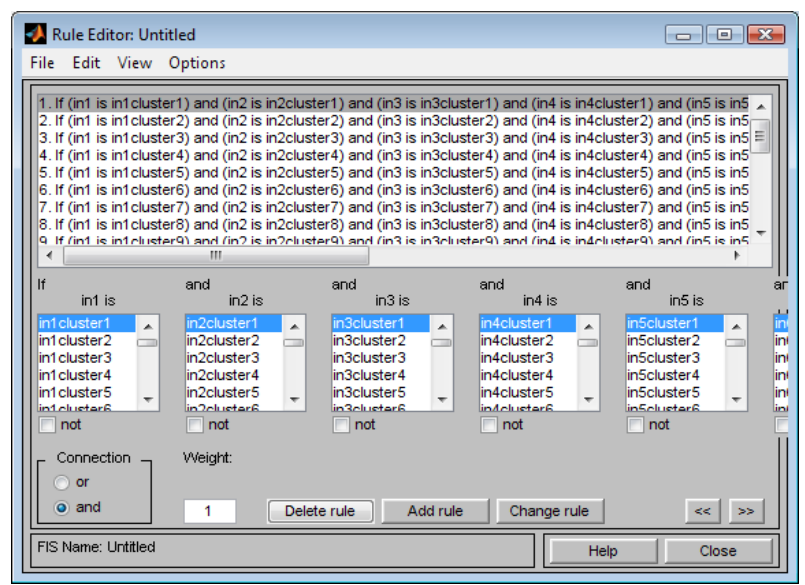

Fig. 3 Fuzzy rules editor.

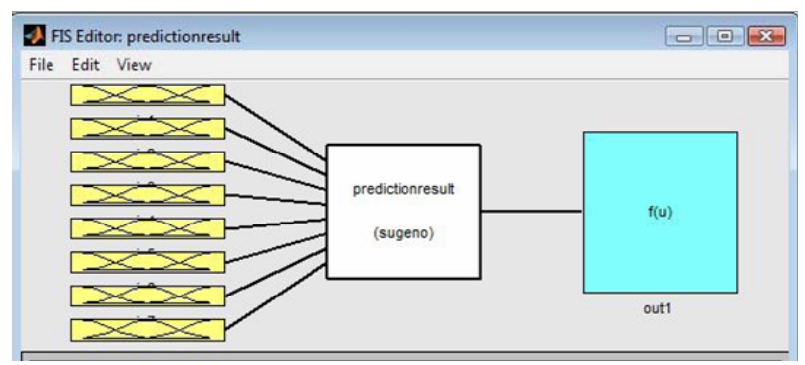

Fig. 4 Fuzzy rules inference engine. 


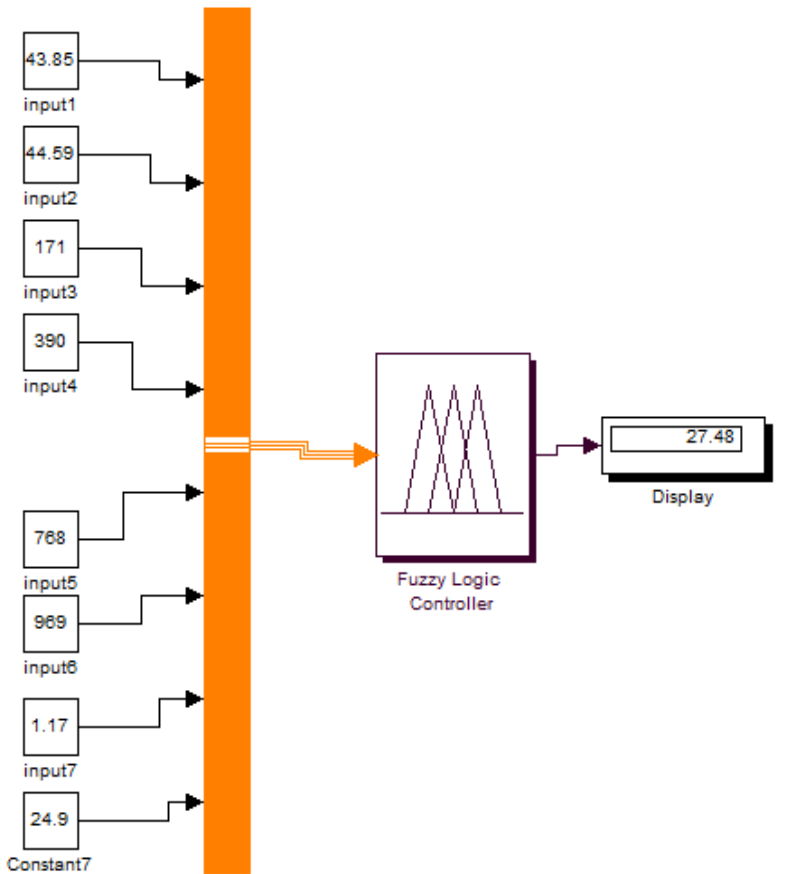

Fig. 5 Blockdiagram of the prediction model control system using fuzzy controller.

aggregate size of $25 \mathrm{~mm}$ and slump of $12-15 \mathrm{~cm}$. The reason to choose this set of data is, the large number of concrete mixes (which meana large number of samples) and these mixes were from different plants of ready mix concrete, and this is also a good prove that the proposed model could valid even for ready mix concrete. Another reason that these data were from Korea, so, this is also a good prove that the model could work for any type and any place in spite of variation of the data.

Variation in concrete strength of the test specimens depends on how well the materials, concrete manufacture and testing is controlled. Especially, construction practices may cause variation in strength of in-situ concrete due to inadequate mixing, poor compaction, delay and improper curing.

The variables available in the data are mix proportions, i.e., the percent of materials used in the mix and slump test results with the percent of the admixture material.

\section{Results and Discussion}

It is very important to analyze the effect of mix constituents on strength of concrete.

Mix design is a specific combination of raw materials that are used in a particular concrete to reach a given target strength. So the significant factor in 28 days compressive strength is the concrete composition. Concrete theory suggested that water to cement ratio $(\mathrm{w} / \mathrm{c})$ of concrete is a primary factor influencing the strengthening process, both the final strength and the rate of hardening are affected. Also, it is well known that decreasing water content increases strengthof theconcrete. Furthermore, strength of concrete is

Table 1 Physical properties ofthe materials.

\begin{tabular}{|c|c|c|}
\hline Materials & Min & Max \\
\hline $\begin{array}{l}\text { Cement OPC } \\
\text { Specific gravity }\end{array}$ & 3.14 & 3.15 \\
\hline $\begin{array}{l}\text { Fine aggregate } \\
\text { Specific gravity }\end{array}$ & 2.59 & 2.61 \\
\hline F.M for fine aggregate & 2.70 & 2.97 \\
\hline $\begin{array}{l}\text { Coarse aggregate (crushed } \\
\text { stone)specific gravity }\end{array}$ & 2.6 & 2.67 \\
\hline F.M for coarse aggregate & 6.5 & 7.21 \\
\hline
\end{tabular}

Table 2 Mix proportions with compressive strength.

\begin{tabular}{llllllllll}
\hline \multirow{2}{*}{ No. } & w/c & S/a & \multicolumn{4}{c}{ Weight of unit volume $\left(\mathrm{kg} / \mathrm{m}^{3}\right)$} & \multicolumn{3}{c}{ Compressive strength (MPa) } \\
\cline { 3 - 9 } & $\%$ & $\%$ & $W$ & $C$ & $S$ & $g$ & Agent & 7 days & 28 Days \\
\hline 1 & 60.21 & 51.19 & 174 & 289 & 933 & 900 & 0.86 & 15.5 & 21.2 \\
2 & 59.74 & 52.07 & 184 & 308 & 927 & 860 & 0.91 & 16.3 & 24.2 \\
3 & 60.6 & 52.04 & 183 & 302 & 926 & 860 & 0.91 & 16.3 & 23 \\
4 & 57.48 & 52.7 & 173 & 301 & 961 & 863 & 0.9 & 21.5 & 26.2 \\
5 & 60.32 & 50.9 & 190 & 315 & 904 & 862 & 0.47 & 18.6 & 24 \\
6 & 61.49 & 51.2 & 190 & 309 & 911 & 859 & 0.46 & 17.4 & 22.5 \\
7 & 59.55 & 46.09 & 184 & 309 & 821 & 975 & 0.92 & 15.8 & 22.6 \\
8 & 50 & 48.47 & 164 & 328 & 886 & 942 & 1.64 & 23.2 & 34.7 \\
9 & 47.83 & 45.1 & 176 & 368 & 805 & 988 & 0.77 & 19.1 & 26.9 \\
10 & 49.44 & 48.8 & 178 & 360 & 858 & 914 & 1.08 & 23.3 & 30.7 \\
\hline
\end{tabular}




\begin{tabular}{|c|c|c|c|c|c|c|c|c|c|}
\hline 11 & 52.35 & 47.88 & 178 & 340 & 839 & 931 & 0.51 & 22.6 & 28.8 \\
\hline 12 & 44.47 & 44.9 & 165 & 371 & 810 & 1000 & 1.85 & 20.7 & 27.6 \\
\hline 13 & 44.69 & 47.6 & 164 & 367 & 847 & 940 & 1.84 & 18.9 & 28.5 \\
\hline 14 & 48.56 & 49.63 & 169 & 348 & 882 & 902 & 1.74 & 24.1 & 31.8 \\
\hline 15 & 48.92 & 49.4 & 181 & 370 & 866 & 887 & 1.11 & 23 & 30.5 \\
\hline 16 & 50 & 49.51 & 171 & 342 & 885 & 913 & 1.71 & 23 & 31.6 \\
\hline 17 & 49.73 & 49.93 & 181 & 364 & 865 & 874 & 1.09 & 21.6 & 31.7 \\
\hline 18 & 44.75 & 48.77 & 179 & 400 & 835 & 894 & 2.8 & 22 & 30.2 \\
\hline 19 & 45.34 & 46.14 & 180 & 397 & 790 & 939 & 2.78 & 22.4 & 30.2 \\
\hline 20 & 46.56 & 43.9 & 183 & 393 & 759 & 981 & 1.18 & 20.4 & 29.7 \\
\hline 21 & 50 & 45.99 & 175 & 350 & 804 & 955 & 1.05 & 16 & 29.8 \\
\hline 22 & 47.04 & 44.71 & 183 & 389 & 778 & 962 & 1.17 & 19.8 & 26.7 \\
\hline 23 & 47.3 & 44.71 & 184 & 389 & 778 & 962 & 1.17 & 18.1 & 25.3 \\
\hline 24 & 48.04 & 47.09 & 184 & 383 & 810 & 924 & 1.15 & 20.1 & 27.8 \\
\hline 25 & 48.41 & 47.41 & 183 & 378 & 807 & 902 & 1.13 & 22 & 29.1 \\
\hline 26 & 48.41 & 47.41 & 183 & 378 & 818 & 924 & 1.13 & 22.8 & 29.2 \\
\hline 27 & 47.79 & 47.59 & 184 & 385 & 812 & 922 & 1.16 & 21.2 & 27.6 \\
\hline 28 & 45.69 & 48.32 & 175 & 383 & 846 & 905 & 0.77 & 22.8 & 28.9 \\
\hline 29 & 46.76 & 50.31 & 173 & 370 & 889 & 878 & 1.11 & 21.3 & 27.3 \\
\hline 30 & 46.74 & 50.49 & 179 & 383 & 879 & 862 & 1.15 & 21.2 & 27.6 \\
\hline 31 & 44.21 & 49.01 & 168 & 380 & 868 & 903 & 1.9 & 21.1 & 29.1 \\
\hline 32 & 47.77 & 46.1 & 182 & 381 & 812 & 956 & 0.8 & 20 & 26.2 \\
\hline 33 & 45.14 & 47.2 & 172 & 381 & 815 & 940 & 1.91 & 21.5 & 28.3 \\
\hline 34 & 48.41 & 47.41 & 183 & 378 & 807 & 923 & 1.13 & 20.7 & 27.5 \\
\hline 35 & 45.89 & 43.5 & 184 & 401 & 754 & 978 & 2.01 & 23.7 & 31.3 \\
\hline 36 & 48.56 & 45.8 & 185 & 381 & 800 & 946 & 1.91 & 21.9 & 28.7 \\
\hline 37 & 45.69 & 48.3 & 175 & 383 & 863 & 888 & 1.92 & 20.6 & 28.2 \\
\hline 38 & 47.78 & 45.14 & 172 & 360 & 794 & 965 & 1.08 & 21 & 27.7 \\
\hline 39 & 45.87 & 44 & 189 & 412 & 730 & 947 & 1.65 & 25 & 30.9 \\
\hline 40 & 45.99 & 43.96 & 189 & 411 & 732 & 951 & 1.44 & 20.7 & 30.7 \\
\hline 41 & 42.76 & 46.29 & 180 & 421 & 784 & 927 & 0.85 & 22.7 & 30 \\
\hline 42 & 40.89 & 42.47 & 184 & 450 & 713 & 977 & 1.35 & 22.6 & 30.7 \\
\hline 43 & 40.62 & 42.01 & 184 & 453 & 704 & 983 & 1.59 & 23.6 & 31 \\
\hline 44 & 41.97 & 47.49 & 183 & 436 & 804 & 889 & 0.87 & 22.8 & 29.8 \\
\hline 45 & 44.1 & 48.32 & 187 & 424 & 812 & 882 & 1.27 & 22.4 & 30.2 \\
\hline 46 & 43.57 & 46.8 & 183 & 420 & 785 & 920 & 1.26 & 22.8 & 30.7 \\
\hline 47 & 44.31 & 46.61 & 183 & 413 & 780 & 921 & 1.24 & 23.9 & 30.1 \\
\hline 48 & 44.31 & 46.61 & 183 & 413 & 791 & 923 & 1.24 & 23.6 & 30.9 \\
\hline 49 & 40.98 & 46.42 & 168 & 410 & 811 & 936 & 2.05 & 22.6 & 33.3 \\
\hline 50 & 42.45 & 47.71 & 180 & 424 & 813 & 891 & 1.27 & 22.9 & 30.8 \\
\hline 51 & 44.31 & 46.61 & 183 & 413 & 783 & 956 & 0.87 & 20.8 & 29.3 \\
\hline 52 & 48.4 & 47.6 & 196 & 405 & 786 & 879 & 0.61 & 22.4 & 30.7 \\
\hline 53 & 45.17 & 48.5 & 187 & 414 & 818 & 883 & 1.24 & 22.8 & 29.5 \\
\hline 54 & 44.31 & 46.61 & 183 & 413 & 780 & 900 & 1.24 & 25.9 & 34.3 \\
\hline 55 & 44.31 & 46.6 & 183 & 413 & 783 & 914 & 1.24 & 24.5 & 32.4 \\
\hline 56 & 39.37 & 45.2 & 176 & 447 & 760 & 970 & 1.34 & 24.7 & 29.4 \\
\hline 57 & 43.75 & 44.7 & 182 & 416 & 771 & 954 & 2.08 & 23.4 & 30.8 \\
\hline 58 & 41.47 & 45.5 & 175 & 422 & 782 & 937 & 0.84 & 23.7 & 31.5 \\
\hline 59 & 43.85 & 44.59 & 171 & 390 & 768 & 969 & 1.17 & 24.9 & 30.6 \\
\hline
\end{tabular}


highly affected by cement content andthe amount of fine and coarse aggregate used in the mix as well as any other additional material added to the mix in order to improvethe specific property for the concrete like fly ash, silica fume and slag or admixture like super plasticizer.

\section{The Regression Model}

After analyzing the influence of mix constituent on the strength at the age of 7 and 28 days, the proposed model was used to predictthe compressive strength at the specified ages comprises all the variables mentioned earlier. The full details of the regression model and its development was mentioned earlier in a previous work [17]. The final form of the proposed strength prediction model for both ages was:

$$
f_{28}=a_{0} C^{a_{1}} \cdot W^{a_{2}} \cdot S^{a_{3}} \cdot g^{a_{4}} \cdot \mathrm{Ag}^{a 5} \cdot w / c^{a 6} \cdot S / a^{a^{7}}
$$

The correlation coefficient for the prediction of 28 days compressive strength was 0.7579 . This result considers being good result concerning the variations in the data.

Moreover, there are some relationships in previously published studies that can predict the 28 days compressive strength from 7 days values, or maybe earlier values $[3,4]$. So, if we use the concept of early age, strength to predict the later age, strength in this case, i.e., the strength at 7 days $(f 7)$ will be one of the variables used in the model. The coefficient of correlation in this case will improve significantly from 0.7579 to 0.866 which prove the importance of this concept.

Fig. 6 shows the relationship between the observed (actual) value of the compressive strength, and the predicted values obtained using the proposed model for 28 days.

\section{The Fuzzy Logic Model}

To construct the Fuzzy model data should be dividedto use for training (main part of the data), and the other part should be used for testing the constructed model.For this aim, in the study 49 data experiment results were used, 10 were used to build up the model, i.e., in the training process and 20 were used in the process of testing.

First of all, the effect of each input (each variable used in the prediction model) on the output (compressive strength of concrete) was demonstrated in Fig. 7.

The Procedure for construction of the Fuzzy model was simply explained earlier. After building the model

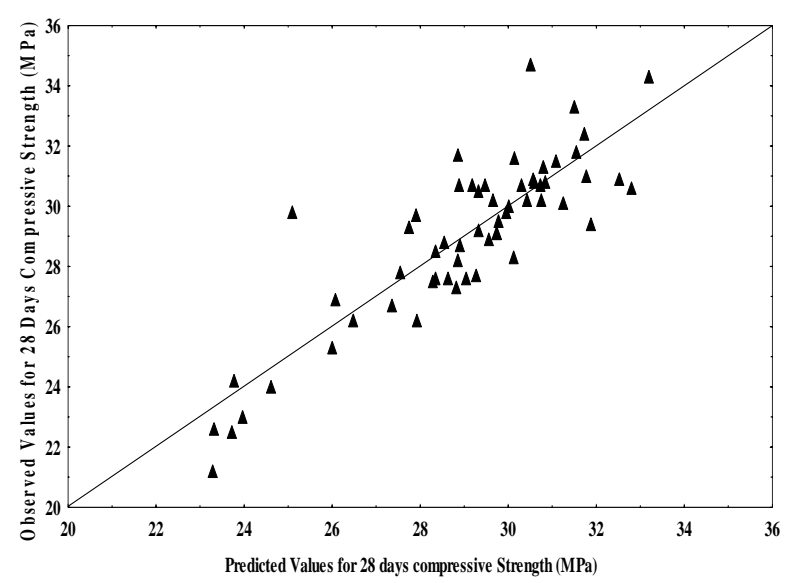

Fig. 6 Relationship between the actual and predicted compressive strength of 28 days.

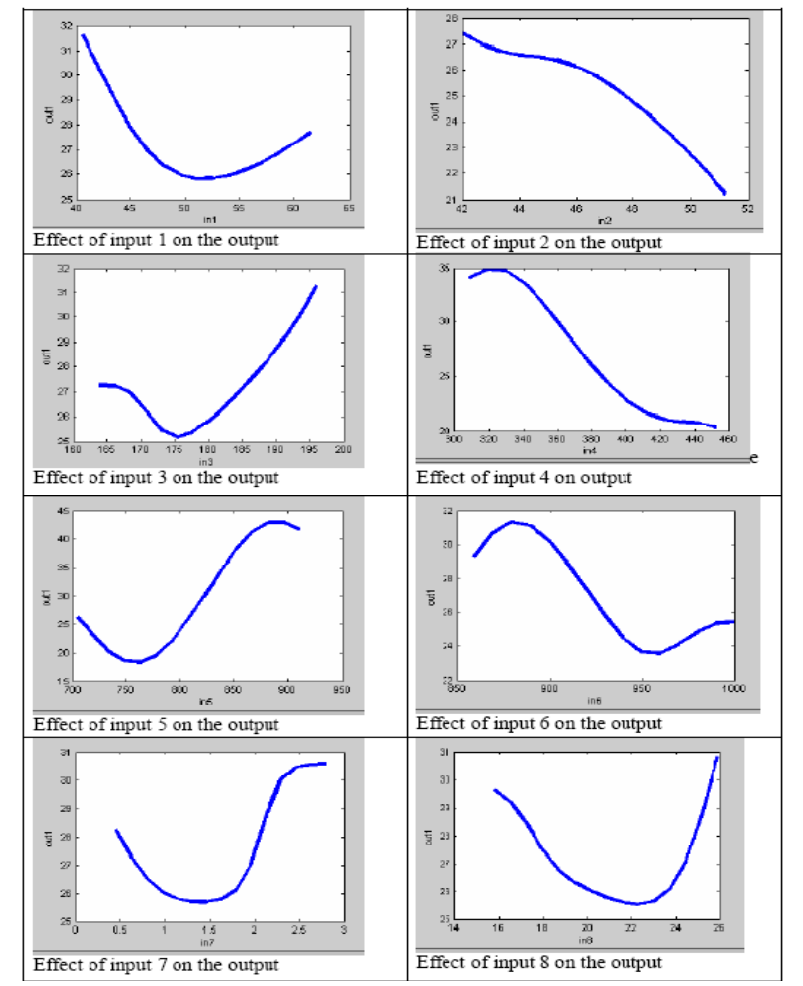

Fig. 7 The effect of inputs to the output. 
Table 3 The values of actual and predicted compressive strength using the fuzzy logic model.

\begin{tabular}{ll}
\hline $\begin{array}{l}\text { Actual 28 days } \\
\text { compressive strength }\end{array}$ & $\begin{array}{l}\text { Predicted 28 days compressive } \\
\text { strength by Neuro-fuzzy model }\end{array}$ \\
\hline 21.2 & 23.11 \\
24.2 & 22.69 \\
23 & 22.65 \\
26.2 & 22.45 \\
24 & 22.48 \\
32.4 & 30.06 \\
29.4 & 30.61 \\
30.8 & 33.24 \\
31.5 & 27.52 \\
30.6 & 27.48 \\
\hline Corr. Coef. & 0.83649 \\
\hline
\end{tabular}

using 98 data available with 8 inputs (the variables available from data, including the value of 7 days compressive strength), the model was tested using the remaining data. The values of actual and predicted compressive strength using the fuzzy logic modelwere listed in Table 3.

\section{Conclusions}

From this study, a mathematical model was developed using two methods. The first method was multiple non-linear regressions and was discussed in previous work. The second method wasthe fuzzy logic system. From this work:

The importance of the influence of mix constituents on the strength of concrete was approved.

Previous models that deal with the prediction of concrete compressive strength, lack of including other variables affecting strength gaining in concrete.

A mathematical model for the prediction of concrete compressive strength at the ages of 28 were proposed and developed (using non-linear regressions) from the knowledge of the mix constituents, i.e., the variables used are the mix proportions elements.

The prediction model developed in this study is: $f_{28}=a_{0} C^{a_{1}} \cdot W^{a_{2}} \cdot S^{a_{3}} \cdot g^{a_{4}} \cdot A g^{a^{5}} \cdot w / c^{a 6} \cdot S / a^{a^{7}}$

These models prove to be used with any set of data in spite of variations in test results of the concrete in question.

The concept of using early age, strength to predict the strength at later ages provedto be valid and could be used successfully.

The technique of Fuzzy logic was used in this work also for the prediction of 28 days compressive strength. The values obtained from both the models were close to the experimental results.

The Fuzzy technique proved to bea powerful tool for the use of strength prediction and easy to use and implement for civil engineer.

\section{References}

[1] N. Hamid-Zadeh, A. Jamali, N. Nariman-Zadeh, Polynomial model for concrete compressive strength prediction using gmdh-type neural networks and genetic algorithem, in: ICOSSE'06 Proceedings of the 5th WSEAS International Conference on System Science and Simulation in Engineering, 2006, pp. 13-18.

[2] D. Williams, Concrete strength prediction of early-age data-technical paper, Honor Project, Technical Paper, University of Adelaide.

[3] M.A. Suhad, Mathematical model for the prediction of cement compressive strength at the ages of $7 \& 28$ days within 24 hours, MSc Thesis, Al-Mustansiriya University, 2001.

[4] G.F. Kheder, A.M. Al-Gabban, M.A. Suhad, Mathematical model for the prediction of cement compressive strength at the ages of $7 \& 28$ days within 24 hour materials and structures, RILEM Publications SARL 264 (2003) (36) 693-701.

[5] I.B. Topçu, M. Sarıdemir, Construction and Building Materials, Construction and Building Materials 22 (4) 532-540.

[6] M. Pala, E. Ozbay, A. Öztas, M.I. Yuce, Appraisal of long-term effects of fly ash and silica fume on compressive strength of concrete by neural networks, Construction and Building Materials 21 (2007) 384-394.

[7] J. Hole, K. Schabowicz, Mathematical-Neural Model for Assessing Productivity, Journal of Civil Engineering and Management 13 (1) (2007) 47-54.

[8] I.B. Topçu, M. Sarıdemir, Prediction of properties of waste AAC aggregate concrete using artificial neural network, Computational Materials Science 41 (1) (2007) 117-125.

[9] I.B. Topcu, M. Sarıdemir, Prediction of compressive strength of concrete containing fly ash using artificial neural network and fuzzy logic, Computational Materials Science 199 (1-3) (2008) 108-118.

[10] S. Popovics, Analysis of concrete strength versus water-cement ratio relationship, ACI Material Journal 87 (5) (1990) 517-529. 
[11] L.A. Zadeh, Fuzzy sets, Information and Control 8 (1967) 38-53.

[12] Z. Sen, Fuzzy algorithm for estimation of solar irradiation from sunshine duration, Solar Energy 63 (1998) 39-49.

[13] H.Labeling, on finding a compromise solution in multi-criteria problems using theFuzzy Min-Operator. Fuzzy Sets and Systems 6 (1981) 105-110.

[14] X.Huang, Two new models for portfolio selection with stochastic returns taking fuzzy information, Eur. J. Oper, Res 180 (2007) 396-405.

[15] JN. Sheen, Fuzzy financial profitability analyses of demand side management alternatives from participant perspective, Inf. Sci. 169 (2005) 329-364

[16] J.Naming, Y. Sangchun, C. Hongbum, Prediction of compressive strength of in-situ concrete based on mixture proportion, Journal of Asian Architecture and Building Engineering 3 (1) (2004) 9-16.

[17] M.F.M. Zain,S.M. Abd, Mathematical Regression Model for the Prediction of Concrete Strength, in: MAMECTIS'08 Proceedings of the 10th WSEAS International Conference on Mathematical Methods, Computational Techniques and Intelligent Systems, pp. 396-402, World Scientific and Engineering Academy and Society (WSEAS) Stevens Point, Wisconsin, USA, 2008. 